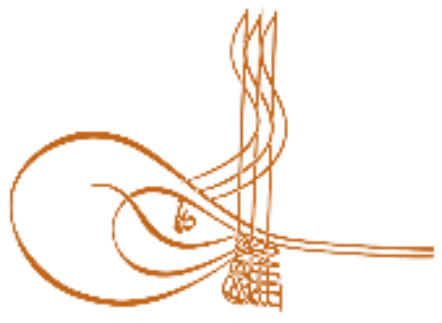

www.turkishstudies.net/social
Turkish Studies - Social Sciences

eISSN: $2667-5617$

Research Article / Araștırma Makalesi

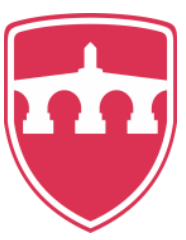

INTERNATIONAL

BALKAN

UNIVERSITY

Sponsored by IBU

\title{
Depo Tasarımı ve Sistemlerinin Gıda Sektöründe Uygulaması
}

\author{
Application of Warehouse Design and Systems in Food Sector
}

\author{
Ahmet Alper Sayın* - Haşim Barman**
}

\begin{abstract}
In today's world, due to the competitive market, the amounts of goods and services are given by consumers in all sectors. For this reason, companies significantly reduce their profit rates in their production. Companies need to provide a minimum cost to increase these falling profits. Therefore, companies focus on warehouse design; It has become an imperative to create a warehouse design that is suitable for the technological age, will increase the rate of profit and reduce costs. In the definitions made, logistics is the flow and storage of customer requests from the starting point to the consumption point with the correctness of logistics. There are serious researches related to warehouse design, which is one of the most important processes of logistics. If the warehouse design is provided correctly, the companies increase the supply chain network to an efficient level and have a great advantage against their competitors. Warehouse systems used in conjunction with warehouse design increase work efficiency in the enterprise and ensure their formation in corporate memory. In our study, the warehouse design and systems used by a company operating in the food sector in the Organized Industrial Zone of Karaman were discussed and positive effects on the efficiency of the company were determined. It has been stated by the business administration that there are some deficiencies compared to the systems and designs used in similar companies in the sector, and their installation costs will be met in time, and it has been stated that the studies have started to eliminate the deficiencies. Since the study was carried out only in Karaman province and in one firm, also due to the fact that the company operates in the international market, all data could not be generalized.
\end{abstract}

Structured Abstract: Introduction In a globalizing world, the fact that all consumers can reach what they want at any time caused the growth of the competitive environment among companies. Therefore, in order to gain an advantage both in the market and in a competitive environment, they concentrate more on the sale of goods than the production of companies. At this stage, the provision of services at the least cost has been the right way to gain competitive advantage.

\footnotetext{
* Dr. Öğr. Üyesi, Karamanoğlu Mehmetbey Üniversitesi, Uygulamalı Bilimler Yüksekokulu, Uluslararası Ticaret ve Lojistik Yönetimi Bölümü

Asst. Prof. Dr., Karamanoglu Mehmetbey University, School of Applied Sciences, International Trade and Logistics Management

ORCID 0000-0002-2086-6763

ahmetalpersayin@kmu.edu.tr

*** Karamanoğlu Mehmetbey Üniversitesi, Sosyal Bilimler Enstitüsü

Karamanoglu Mehmetbey University, Social Sciences Institute

ORCID 0000-0002-1833-0871

mail adresi

Cite as/ Atıf: Sayın, A. A., Barman, H. (2020). Depo tasarımı ve sistemlerinin gıda sektöründe uygulaması, Turkish

Studies - Social, 15(3), 1445-1455. https://dx.doi.org/10.29228/TurkishStudies.41638

Received/Geliş: 06 February/Şubat 2020

Checked by plagiarism software

Accepted/Kabul: 25 April/Nisan 2020

Published/Yayın: 30 April/Nisan 2020

Copyright $(C)$ INTAC LTD, Turkey

CC BY-NC 4.0
} 
Storage and transportation, which is the leading logistics activity, needs to be controlled in the most perfect way. It is important for the company to achieve the maximum efficiency of the process from the entry and exit of any goods to the warehouse, and to create plans for the future and to relate them to the company.

In this study, the warehouse design and systems used by a company operating in the retail sector in Karaman province, using the in-depth interview technique, which is one of the qualitative research methods in scientific research technique, were examined. Thanks to today's technologies used in the company's existing warehouse, warehouse efficiency has been ensured, thus, it has been determined that the company produces more with less cost. It is emphasized that the company should follow the developments in today's world where new technologies are emerging day by day and it is emphasized that necessary steps should be taken in order not to be deprived of these technologies.

\section{Method}

In this study, it is to reveal the importance of storage and storage concepts, which are the biggest weapon of firms in today's competitive market, and to emphasize that storage should be arranged in accordance with the company's objectives. Firms in a consumer-dominated market; they have started to give serious importance to warehouse processes in order to provide a better quality, optimum price and a fast service. In this study, it is aimed to explain that the direct effect of warehouse design on firm costs and efficiency in warehouse design are directly proportional to firm profitability, by using an interview and observation method in an example firm.

In the study, the importance of the concepts of warehouse and storage in the logistics industry is explained. In this process, it has been explained with an exemplary application that the company will increase the profit and reduce the costs if it is effectively applied at every stage of the warehouse design by taking advantage of the current developments. It is foreseen that the examinations carried out at the company will contribute to the future studies of the enterprises and researchers.

\section{Findings}

Storage, which is one of the leading logistics processes, affects other stages of logistics to a great extent. If this storage process is successful, all processes of logistics will be positively affected. The most important element of success in the storage process is the construction and use of the warehouse design in accordance with today's technologies. The fact that the analyzed company has a large smart warehouse, making effective use of information technologies and using all other technological tools in the warehouse has provided a great benefit to the company. Using the SAP system, the company provides successful addressing and placement on an area of $40,000 \mathrm{~m}^{2}$ with only 5 employees and reduces costs by around $80 \%$. In addition, thanks to the SAP system used, orders are prepared with only 1 person and in just 30 minutes, providing a great advantage to the company in terms of speed and time. Prepared orders are shipped quickly thanks to modern equipment. With the smart sensors used in lighting in the warehouse, energy saving is ensured and it can be monitored for 24 hours thanks to the established mixes. Having a smart warehouse, the company reduces the number of employees by $80 \%$, minimizes costs and reduces the error level to zero.

\section{Conclusions and Suggestions}

Logistics processes meant only transport and stock keeping at first. Logistics has reached a level that can provide all of the services over time. The expression of logistics that draws attention with the increasing importance of logistics processes briefly; these are all the stages of planning, implementation and control to ensure the active and appropriate flow of products and services from the manufacturer to the consumer, depending on the wishes and needs of the consumers. In the event that these processes start operating in accordance with technology and successfully, they can gain a voice in the world for companies.

In case the company uses the automatic rail rack system in the warehouse; More efficiency will be achieved in terms of cost, speed, labor support, reliability, robustness and professionalism. In addition, the installation of a heating system, which will provide a constant temperature in the company's existing warehouse, will be suitable both for workers and for the health of products.

Keywords: Logistics, Warehouse Design, Warehouse Systems 
Öz: Günümüz dünyasında, rekabet piyasasından dolayı sektörlerin hepsinde mal ve hizmetlerin tutarları tüketiciler tarafindan verilmektedir. Bundan dolayı şirketler, üretimlerinde kar oranlarını ciddi oranda azaltmaktadırlar. Şirketler, düşen bu kar oranlarını fazlalaştırmak için minimum maliyeti sağlamaları gerekmektedir. Bu nedenle, şirketler depo tasarımına yoğunlaşarak; teknoloji çağına uygun, kar oranını artıracak, maliyetleri azaltacak bir depo tasarımı oluşturmaları bir zorunluluk haline gelmiş̧tir. Yapplan tanımlamalarda lojistik, müșteri isteklerinin lojistiğin doğruları ile başlangıç noktasından tüketim noktasına kadar akışı ve depolanmasıdır. Lojistiğin en önemli süreçlerinde olan depo tasarımı ile alakalı günümüzde ciddi araştırmalar mevcuttur. Depo tasarımının doğru bir şekilde sağlanması halinde, firmalar tedarik zinciri ağını verimli bir düzeye getirmekte ve rakiplerine karşı büyük bir avantaj sahibi olmaktadırlar. Depo tasarımı ile birlikte kullanılan depo sistemleri, işletmede iş verimliliğini artırarak, kurumal hafızanında oluşmasını sağlamaktadır. Çalışmamızda, Karaman Organize Sanayi Bölgesinde gıda sektöründe faaliyet gösteren bir firmanın, depo tasarımı ve depoda kullandığı sistemler ele alınmış olup şirketin verimliliğine olumlu etkileri tespit edilmiştir. Sektörde yer alan benzer firmalarda kullanılan sistem ve tasarımlara kıyasla bazı eksikliklerin olduğu, bunların kurulma maliyetlerinin zaman içerisinde karşılanacağı işletme yönetimince de belirtilmiş, eksikliklerin giderilmesi için çalışmaların başladığı ifade edilmiştir. Çalışma, sadece Karaman ilinde ve tek firmada yapıldığından dolayı ayrıca firmanın uluslararası pazarda faaliyet göstermesinin etkisiyle, tüm verilere izin verilmemesi nedeniyle genelleme yapılamamıştır.

Anahtar Kelimeler: Lojistik, Depo Tasarımı, Depo Sistemleri

\section{Giriş}

Küreselleşen dünyada bütün tüketiciler istediklerine diledikleri zamanda ulaşabilmeleri, şirketler arasında rekabet ortamının büyümesine neden olmuştur. Bundan dolayı hem pazarda hem de rekabet ortamı içinde avantaj sahibi olmak için şirketlerin mal üretiminden daha çok mal satışına yoğunlaşmışlardır. Bu aşamada, hizmetlerin en az maliyet ile gerçekleştirilmesi rekabet avantajı elde etmenin en doğru yolu olmuştur.

Lojistik, depolamanın da dahil edilerek gerçekleştirilen faaliyetler bütünü olmaktadır. Lojistik; taşıma, depolama, dağıtım ve stok yönetimi gibi dağıtım sürecinde gerçekleştirilen işlevlerin yönetilmesidir.

Lojistik faaliyetlerin başında gelen depolama ve taşımacılık, en mükemmel bir şekilde kontrol edilmesi gerekmektedir. Herhangi bir malın depoya girişinden, çıkışına kadar olan prosesin maksimum seviyede verimlilik elde etmek ve gelecek için planların oluşturulup bunların şirketle bağdaşması, şirket için önemli olmaktadır.

Bu çalışmada Karaman ilinde, perakende sektöründe faaliyet göstermekte olan bir firmanın, bilimsel araştırma tekniğinde nitel araştırma yöntemlerinden derinlemesine mülakat tekniğgi kullanılarak, firmanın depo tasarımı ve kullandığı sistemler incelenmiştir. Firmanın mevcut deposunda kullanılan günümüz teknolojileri sayesinde depo verimliliği sağlanmış bu sayede firma daha az maliyet ile daha fazla üretim yaptığı saptanmıştır. Firmanın her geçen gün, yeni teknolojilerin ortaya çıktı̆̆ 1 günümüz dünyasındaki gelişmeleri yakından takip etmesi gerekmekte olup bu teknolojilerden mahrum kalmaması için gerekli adımları atılması gerektiği vurgulanmıştır.

\section{Depolama Kavramı ve Önemi}

Lojistiğin ana çatısı hammadde, yarı ürün ve nakliye işlemidir. Ürün ilk aşamadan son aşamaya gelinceye kadar bazı durumlarda taşıması durmaktadır. Bunlardan bazıları; nakliye vasıtası değiştiğinde, ürüne ekleme veya azaltma işlemi yapıldığında ve ürünün teslim zamanıdır. Bu ürün hareketinin durakladığı noktalar; depo, dağıtım merkezleri, aktarım merkezleri, transfer merkezleri, antrepo, ambar gibi isimlendirilen yerlerdir. Depolama, ürünün sabit kaldığı yani sıfır hızında bir nakliye şeklinde ifade edilmektedir (Yıldıztekin 2004; 33) 
Depo kavramı, ürünün güvenliğini sağlamak, ürünü gizlemek, istenildiğinde kullanmak üzere ürünün yerleştirildiği ardiye şeklinde ifade edilmektedir. Depolar, ürünün ilk aşaması olan hammaddeden, son aşamasına gelinceye kadar geçen süreçte stratejik bir rolü olan yerlerdir.

Kısaca ifade edecek olursak depo, malların ilk aşaması olan hammadde sürecinden, üretim sürecine ve üretim sürecinden tedariki sağlanacak en son noktaya gelene kadar geçen süreçte, stratejik bir rolü olan mekânlardır. Depolama ise malların üretilmesinden, ihtiyaç duyulacak hale gelene kadar güvenli bir ortamda saklanmasıdır (Acar, 2010).

Depo, günümüz ticaret dünyasında tedarikçi, üretici, dağıtıcı ve perakendeciler açısından ciddi bir öneme sahiptir. Depolar, dünya ticaretinde de ihracat, ithalat ve gümrük aşamasında ürünlerin korunduğu, saklandığı, güvenliğinin sağlandığı ve sevk edilebilir hale geldiği yerler oldukları için şirketler açısından son derece önemlidir.

İşletmeler için en büyük hizmet aracı depolardır. Ürünlerin ilk aşamasından nihai aşamaya varıncaya kadar bütün süreçlerde depolama mevcuttur. Depo, lojistik sektöründe ürüne değer katma yeri olarak görev yapmaktadır.

Depo ve depolama kavramları, ayrı bir ihtisas alanı olmuş ve lojistik sektörünün vazgeçilmez bir parçası haline gelmiştir. Lojistik süreçlerin vaktinde ve başarılı olarak yapılması, ürünün özelliğine göre sağlam bir şekilde yerleştirilmesi, depolanması ve bilgisayar aracılığıyla kaydedilmesi gerekmektedir. Lojistik şirketlerin depolama faaliyetlerini kullanmasıyla beraber, ticari şirketlerin depolama maliyetlerini minimum seviyeye indirmesi ve ürünlerin vaktinde istenilen pazara ulaştırılması büyük bir önem verilmesi gereken bir süreçtir (Akal, 1993).

\section{Depo Tasarımı}

Depolar günümüzde rekabet koşulları gereği lojistik faaliyetlere destek veren en önemli unsurlardandır. Deponun firmanın hedeflerine ulaşabilmesi için depo tasarımına ilişkin sürecin optimum bir şekilde uygulanması gerekmektedir. El terminalleri, barkod, taşıyıcı-yerleştirici ekipmanlar, depo kodlama sistemleri, etkin bir yazılım, ve bilişim teknolojilerindeki son gelişmelerden faydalanacak bir depo tasarımının oluşturulması gerekmektedir (Baskak, 2002).

Depo tasarımı, personel ve ekipman sayılarının belirlenmesi, hangi ekipmanlar ile çalışılması gerektiğinin belirlenmesi, raf sisteminin seçimi, ürünlerin mevsimsellik ve siparişlerin dönemsellik niteliklerine uygun bir stratejinin çizilmesi vb. süreçlerin belirlenmesini barındırmaktadır (Tomkins ve Harmelink, 2004).

Depolama sistemi ise raflı depolama, rafsız depolama ve silolarda depolama olmak üzere üç şekilde uygulanmaktadır. Depolanacak olan ürünlerin özelliklerine ve depo alanının fiziksel özeliklerine göre en uygun depolama sistemi seçilmektedir (Dinç, 2010).

Günümüzde ürün çeşitliliğinin fazla olması ve aynı şekilde rakiplerin çok olması ve buna karşılık memnun edilemeyen tüketici kitlesini barındıran bugünün pazar ortamında depo tasarımının stratejik bir rolü bulunmaktadır. Bu durumda firmalar depo tasarımlarına gereken önemi vermek zorunda kalmışlarıdır. Geleneksel yöntemler kullanılarak kurulan klasik sisteme sahip depolar ile modern sisteme sahip depolar arasında ciddi farklar bulunmaktadır. Bu farklar aşağıdaki tabloda belirtilmiştir. 
Tablo 1: Klasik Sistem ve Modern Sistem Farkları

\begin{tabular}{|c|c|}
\hline KLASİK SíSTEM & MODERN SiSTEM \\
\hline Maksimum iş̧i sayısı ve maliyeti & Minimum işçi sayısı ve maliyeti \\
\hline Yavaş bir işleyişe sahip bir depo tasarımı & $\begin{array}{c}\text { Bütün alanlarında hızlı bir işleyişe } \\
\text { sahip bir depo tasarımı }\end{array}$ \\
\hline Teknolojiden sınırlı bir verimlilik & $\begin{array}{c}\text { Bütün alanlarında teknolojik bir } \\
\text { sistem }\end{array}$ \\
\hline Dağınık bir depo sistemi & Düzenli bir depo sistemi \\
\hline $\begin{array}{c}\text { Daha kü̧̧ük alanda fazlaca maliyetli } \\
\text { depolar }\end{array}$ & Büyük ve minimum maliyetli depolar \\
\hline $\begin{array}{c}\text { Yerleştirme ve adreslemede karmaşık bir } \\
\text { depo }\end{array}$ & $\begin{array}{c}\text { Başarılı bir yerleştirme ve } \\
\text { adreslemeye sahip depo }\end{array}$ \\
\hline Daha yavaş ürün sevkiyatı & Daha hızlı ürün sevkiyatı \\
\hline $\begin{array}{c}\text { Her türlü olaylara karşı dayanıksız bir } \\
\text { depo }\end{array}$ & \begin{tabular}{c} 
Bütün olaylara karşı güvnli bir depo \\
\hline $\begin{array}{c}\text { Sınırlı bir hizmet sunan depolama } \\
\text { ekipmanları }\end{array}$ \\
Maksimum düzeyde verimli \\
depolama ekipmanları
\end{tabular} \\
\hline
\end{tabular}

Yukarıdaki tabloda görüldüğü üzere modern bir sisteme sahip bir depo firmaya bütün alanlarda bütük bir verimlilik sağlamaktadır.

\section{Gıda Sektöründe Depo Tasarımı ve Depo Sistemleri}

Rekabetin maksimum seviyede olduğu günümüz ekonomisinde lojistik, bir firmanın diğer bütün alanlarda üretim yapan firmalara karşı büyük bir avantaj sağlamaktadır. Tüketicinin istek ve ihtiyaçlarına göre değişiklik gösteren ve yenilenen, buna bağlı olarak da rekabetin en fazla görüldüğü alanlardan birisi de gıda sektörü olmaktadır.

Firmalar bu sektörde rekabet avantajı elde etmek ve kar oranlarını arttırmak için lojistik süreçleri minimum maliyet ile optimum şekilde uygulamayı amaçlamaktadırlar. Lojistik süreçlerinden biri olan depo tasarımı firmalar için büyük bir rekabet avantajı olabilmektedir. Bu bölümde ele alacağımız Modern Çikolata fabrikasının depo tasarımı ve depo sistemleri sektörde birçok firma için örnek teşkil etmektedir.

\section{Araştırmanın Amacı ve Yöntemi}

Bu çalışmada, günümüz rekabet piyasasında firmaların en büyük silahı olan depo ve depolama kavramlarının önemini ortaya koymak ve depolamanın firmanın amaçlarına uygun bir şekilde düzenlenmesi gerektiğini vurgulamaktır. Tüketicinin hüküm koyduğu bir piyasada firmalar; daha kaliteli, optimum fiyat ve hızlı bir hizmet sunabilmek için depo süreçlerine ciddi oranda önem vermeye başlamışlardır. Bu çalışmada depo tasarımının firma maliyetlerine doğrudan etkisinin ve depo tasarımındaki verimliliğin firma karlılığıyla doğru orantılı olduğunu, örnek bir firmada mülakat ve gözlem metodu kullanılarak açıklanması amaçlanmıştır.

\section{Araştırmanın Kısıtlııkları}

Araştırmada, sektörde faaliyet gösteren firmaların bütününe ulaşılamayacağ için araştırma örneklem ile sınırlıdır. Ayrıca araştırmada kullanılan veri toplama araçları mülakat ve gözlem ile sınırlıdır. Firmanın gizlilik politikası gereği bazı bilgilere ulaşılamaması araştırmanın kısıtlılıklarıdır.

\section{Araştırmanın Bilime Katkısı}

Çalışmada, lojistik sektöründe depo ve depolama kavramlarının önemi açıklanmıştır. $\mathrm{Bu}$ süreçte depo tasarımının her aşamasında günümüz gelişmelerinden faydalanarak etkin bir şekilde uygulanması halinde firmanın karını arttıracağı ve maliyetleri azaltacağı örnek bir uygulama ile 
açıklanmış olup bunun önemi izah edilmiştir. Firmada yapılan incelemeler, işletmelerin ve araştırmacıların ilerde yapacakları çalışmalara katkı sağlayacağı öngörülmektedir.

\section{Firma Bilgisi}

Modern Çikolata ilk olarak 1970'li yıllarda 20 kişinin çalıştığı küçük ve mütevazı bir gofret üretimiyle işe başlamıştır. Modern çikolata daha sonra büyüyerek bir çikolata imalat devi olan Ülker ile 1999'da ortak olmuştur. 2014'te bu ortaklık son buldu ve modern çikolata bütün yönleriyle kendini geliştirerek modern bir fabrika haline gelmiştir. Ülkemiz iç ve diş ticaretinde büyük bir katkısı olan modern çikolata azim ve cesaretiyle hala büyümeye devam etmektedir (www.moderncikolata.com.tr).

Firmanın mevcut yapısıyla ilgili bilgiler aşağıdaki gibidir:

- Firma Karaman Organize Sanayi Bölgesinde bulunmaktadır.

- Firmanın geçmişi yaklaşık olarak 30 yıl'dır. Modern Çikolata adıyla 2014'ten beri hizmet vermektedir.

- Firmada çalışan işçi sayısı yaklaşık olarak 3000 kişidir.

- Firmada perakende sektöründe ciddi rakamlarda ihracat ve ithalat yapmaktadır.

Firmanın bazı iş stratejileri şunlardır:

$\checkmark$ Ürün ve hizmetlerde kaliteyi arttırarak müşteri memnuniyetini sağlamak

$\checkmark$ Büyüyen teknolojiye yatırım yaparak iş verimliliğini maksimum seviyeye çıkarmak,

$\checkmark$ Çalışanlarla sürekli iletişim halinde olan katılımcı ve yeniliğe açık anlayışıyla motivasyon sağlamak,

$\checkmark$ Kanunlara uymak,

$\checkmark$ Kalite, güvenilirliği belgelemek,

$\checkmark$ Firmanın bütün süreçlerinde insanlara ve doğal çevreye karşı duyarlı olmak.

Şirketin amacı; gelişmiş teknoloji ile üretim gücüne sahip çok maliyetli bir ürün örneği ile çalışan, en minimum zamanda tüketicinin istek ve ihtiyaçlarına uyum sağlamak ve bu istek ve ihtiyaçları karşılayan ürün çeşitliliğiyle öncü bir şirket olmayı amaçlamaktadır.

\section{Firmanın Faaliyet Alanları}

Faaliyet alanlarında bisküvi, çikolata, kek, kraker, çikolata bar, gofret ve kremalı çikolata olmak üzere 7 ana kategoride 300'den fazla ürün bulunmaktadır. Ağırlıklı olarak çikolata ve bisküvi alanında üretim yapan firma aylık minimum sezonu 10.000 ton üretim yapmaktadır. Bu gelişen firma iki marka ile Türkiye'ye ve dünyaya açılmaktadır. Bunlar;

\section{Aldiva}

Bestfood

Modern çikolata 90 ülkeye Aldiva markasıyla ihracat yaparak ülke ekonomisine büyük bir katkı sağlamaktadır.

\section{Firmanın Bilgi Yönetim Süreci}

İşletmenin, içinde ve dışında olan tüketici sipariş ve döküm malumatlarının gizlenmesi, ele alınması ve belgelenip raporlanması, ayrıca tüketici ve üreticiye göre stok tahmin ve strateji planlamalarının, iş sürecinin kontrolü ve bütün bu süreçler esnasında ve daha sonra ihtiyaç duyulan 
bilgi akışının gerçekleştirilmesi, bütün süreçlerin denetiminin kolaylıkla yapılmasını sağlamak amaciyla SAP sistemini kullanılmaktadır.

\section{Mevcut Depo Binası}

Karaman'da faaliyet gösteren Modern Çikolata'nın $40.000 \mathrm{~m}^{2}$ kapalı bir depo alanına sahiptir. Bu depolama alanının $20.000 \mathrm{~m}^{2}$ 'si nihai ürün deposu, $20.000 \mathrm{~m}^{2}$ alanı ise ambalaj yani ürün öncesi hammadde deposu olmaktadır. 90 ülkeye üretim yapan firmada bu büyüklükte bir deponun olması firmanın gelişimi ve büyümesi açısından son derece önemlidir.

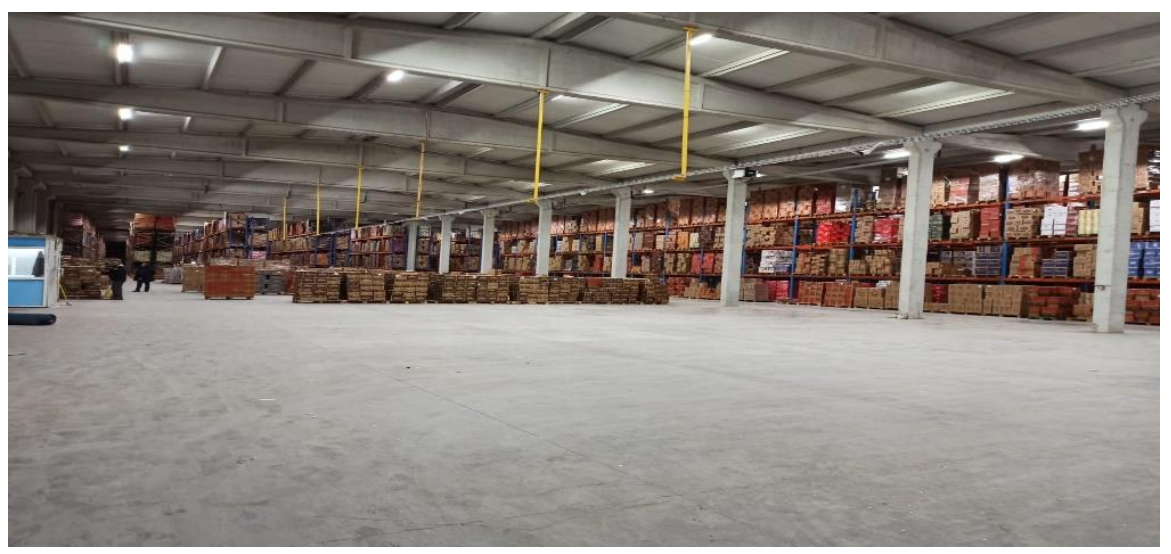

Resim 1: Mevcut Depo Görünümü

Nihai ürün deposunda 11 koridor bulunmakta olup, 19.500 palet kapasitesi bulunmaktadır. Talebe ve adrese bağlı olarak üretimin yapıldığı bu depoda, ürün fazlası oluşmamakta, piyasaya göre ürün çıkarılmakta, ani yaşanacak krizlerden minimum seviyede etkilenme ve var olan piyasaya kolaylıkla uyum sağlanabilmektedir.

\section{Depo İş Süreçleri}

\section{Depo Alanı}

Firmanın depo alanı $40.000 \mathrm{~m}^{2}$ kapalı alana sahip bir deposu mevcuttur. Firmanın nihai depo alanında palet bazlı olarak 19.500 paletlik alan mevcuttur. Bu depo alanı firmaya yeterli olmaktadır. Aylık minimum üretim kapasitesi 10.000 ton olan firmanın böyle bir depoya sahip olması rakiplerine karşı hız, zaman ve maliyet alanında büyük bir avantaj sağlamaktadır. Depo, geniş bir alana sahip olduğu için, dizayn açısından düzgün bir depo görünümündedir.

\section{Ürün Yerleștirme}

Firmanın mevcut deposu büyük olduğundan dolayı çalışanların hangi ürünün nerede yer aldığını bilmesi çok zordur. Burada istenilen depodaki talep edilen ürünün nerede yer aldığını sistematik bir şekilde belirlenmesidir. Bunu sağlamak için firma depoda SAP sistemini kullanmaktadır. Bu sistem sayesinde üretim aşamasından gelen ürün paletli bir şekilde gelmekte olup daha sonra sistem sayesinde depodaki en uygun yer personele tarif edilir ve operatör sayesinde palet depoya yerleştirilir.

Depoda başarılı bir adresleme sistemini sağlamak için depo sahaları bölümlere ayrılmış olup hepsi ayrı ayrı isimlendirilmiştir. Depoda bütün rafların bir numarası bulunmaktadır. Ayrıca depoda bulunan 11 koridora farklı isimler verilmiştir. Firmanın böyle başarılı bir yerleştirme ve adresleme sürecinin olması ürünlerin zamanında ve daha hızlı sevk edilmesini, maliyetlerin azaltılmasını ve düzenli bir depoya sahip olunmasını sağlamaktadır. 


Tablo 2: Klasik Sistem ve Modern Sistem Maliyet Farkları
\begin{tabular}{|c|c|}
\hline KLASİK SíSTEM & MODERN SíSTEM \\
\hline İşçi sayısı: 30 Kişi̇ & İşçi sayısı: 5 Kiş̦i \\
\hline Aylık işçi maliyeti: $76.752 \mathrm{TL}$ & Aylık işçi maliyeti: $12.792 \mathrm{TL}$ \\
\hline Yıllık içi maliyeti: $921.024 \mathrm{TL}$ & Y1llık iş̧i maliyeti: $153.504 \mathrm{TL}$ \\
\hline
\end{tabular}

Tablo 1'de görüldüğü gibi klasik yöntemlerde firmada depo yerleştirme işinde çalışacak olan eleman sayısı 30 kişi iken bu sistem sayesinde 5 kişiye indirilmiştir. Bu sayede ciddi oranda personel maliyetlerinde azalma görülmektedir.

\section{Sipariş Hazırlama}

Depoda sipariş hazırlama aşamasının hızlı olması performans ve verimlilik üzerinde ciddi bir etkisi vardır. Burada önemli olan, ürünlerin siparişi hazırlayan çalışana en optimum şartlarda sunulmasidir.

Firmada kullanılan sipariş toplama sistemi, en hızlı sistem olan palet toplama sistemidir. $\mathrm{Bu}$ sistemde siparişler sevkiyat sorumlusu tarafindan SAP sistemine girilir. Bu sistem sayesinde depo görevlisine bildirim gitmektedir. Bildirimi alan depo görevlisinin, bu bildirimi aldıktan sonra istenilen ürünün hangi koridor, hangi raf ve hangi gözde olduğu hemen belirlenir ve kolaylıkla sevkiyat yapılmaktadır. $\mathrm{Bu}$ sistem firmaya hız ve zaman konusunda büyük bir değer kazandırmaktadır.

Tablo 3: Klasik Sistem ve Modern Sistem Farkları

\begin{tabular}{|c|c|}
\hline KLASİK SíSTEM & MODERN SíSTEM \\
\hline Sipariş hazırlama süresi: $180 \mathrm{dk}$ & Sipariş hazırlama süresi: $30 \mathrm{dk}$ \\
\hline İşçi sayısı: 10 & İşçi sayısı: 1 \\
\hline Minimum aylık işçi maliyeti: $25.584 \mathrm{TL}$ & Aylık işçi maliyeti: $2.558 \mathrm{TL}$ \\
\hline Minimum yıllık işçi maliyeti: $307.008 \mathrm{TL}$ & Yıllık işçi maliyeti: $30.700 \mathrm{TL}$ \\
\hline
\end{tabular}

Tablo 2'de de görüldüğg̈ü üzere sistemin sağlamış olduğu hız tasarrufu olmamış olsaydı, depo içinde bir kişi ile 30 dakikada hazırlanacak olan sipariş, en az 3 saatte hazırlanabilirdi ve bu iş ile ilgili minimum 10 kişinin çalışması gerekirken, şuanda 1 personel ile aynı işlemleri yapabilmektedir.

Firmanın depo konusunda diğer bir prensibi de sipariş hazırlamada FIFO, FEFO ve LIFO prensiplerinden FIFO prensibini kullanmasıdır. Bunları kısaca açıklayacak olursak:

FIFO: Bu teknik ile depoya gelen ilk ürünlerin, önce depodan çıkmasıdır.

FEFO: Bu teknikte ürünlerin son kullanım tarihine göre sevkiyatı yapılmaktadır. Son kullanım tarihi yaklaşan ürünler depodan önce çıkmaktadır.

L LIFO: Bu teknikte ise, depoya son giren ürün ilk olarak çıkmaktadır (Güler, 2006).

FİFO prensibi firmaya, düzenli, güvenli ve daha rahat kullanım alanı sağlamaktadır.

\section{Sevkiyat}

Deponun sevkiyat aşamasındaki en önemli fayda, deponun tek katlı olmasıdır. Aksi halde zaman ve hız açısından olumsuz bir süreç yaşanabilmektedir. Firma, tek katlı depoya sahip olduğu için avantajlı durumdadır.

Siparişler, aracın $\mathrm{m}^{3}$ hesabına göre alınmakta olup buna göre yükleme yapılmaktadır. Yüklemelerde $\mathrm{m}^{3}$ hesabı, araçların verimliliği açısından hassas olarak hesaplanmaktadır. Bir araca kaç palet veya koli sığacağı belli ve sabit omaktadır. Örneğin deniz yoluyla giden siparişlerin konteynır hesapları $70 \mathrm{~m}^{3}$ olmaktadır. 


\section{Aydınlatma, Güvenlik ve Isıtma}

Bir depoda kullanılan doğru bir aydınlatma verimli bir ortam sağlayacaktır. Firmada kullanılan $40.000 \mathrm{~m}^{2}$ 'lik kapalı alanın aydınlatması fabrikanın ana elektrik santraline bağlıdır. Bu büyük alana sahip depo alanında, enerji tasarrufu sağlamak ve minimum seviyede maliyet oluşturmak için sensör aydınlatma özelliği kullanılmaktadır.

Deponun güvenliği ise kameralar ile sağlanmakta olup doğal afetlere karşı da önlemler alınmıştır. Bu önlemler sertifikalar ile de belgelenmiştir.

Depoda 1sıtma sistemi mevcut değildir. Depo içerisinde genellikle nem oranı \% 60 civarındadır. Yaz aylarında herhangi bir problem yaşanma olasılığ 1 düşüktür ama kış aylarında deponun gerekli olan 1sısını kaybetmeyeceği şekilde bir 1sıtma sistemi kurulabilir.

\section{Depo Ekipmanları ve Depolama Yöntemleri \\ Forklit ve Transpalet}

Büyük bir depo alanı bulunan firmanın raf ekipmanları, koşulları kaldırabilecek ve süreci aksatmayacak şekilde olmalıdır. Firmanın gıda sektöründe olması ve depo alanında egsoz dumanının ürünlere etkilememesi için depodaki en önemli raf ekipmanı şarjlı Forklift'ler olmaktadır. Bu sayede daha hızlı, daha güvenilir ve daha verimli bir organizasyon sağlanmıştır. Forklift sayesinde gerek hız, gerek zaman ve gerek maliyet açısından büyük bir tasarruf sağlanmış olup daha optimum bir faaliyet uygulanmıştır. Şarjlı forklift'lerin şarj sorunu da çift akü kullanılarak çözüme kavuşturulmuş bu sayede 7 gün 24 saat hizmet verebilmektedir. Forklift'lerin periyodik bakımları 3 ayda bir yapılmakta olup teknik sorunların oluşması engellenmektedir.

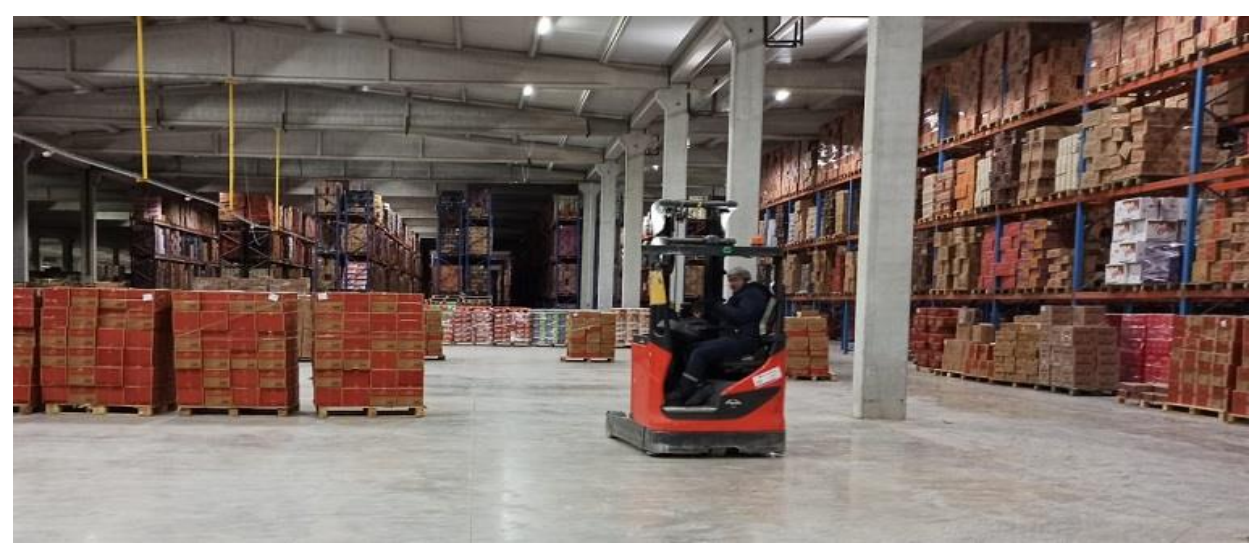

Resim 2: Forklift ve Depo Resmi

Firmada, elle kullanılan transpalet kullanılmakta olup sevkiyatlar araca genellikle bu ekipman sayesinde yüklenmektedir. Transpaletler, kısa mesafedeki ürün yeri değişikliği için de kullanılmaktadır.

\section{Surt Surta Raf Sistemi}

Depoda sırt sırta raf sistemi kullanılmaktadır. Firmalar arasında en çok tercih edilen, minimum maliyet sağlayan ve geniş kullanıma sahip bir depo sistemidir (Kumuk, 2005). Firmada sırt sırta raf sistemi kullanılması sayesinde sistem ile bütün ürün gruplarına direk ulaşmay1, istif makinelerinin rahatlıkla kullanılabilmesi, düzenli, güvenli ve daha geniş kullanım alanı sağlanmaktadır. 


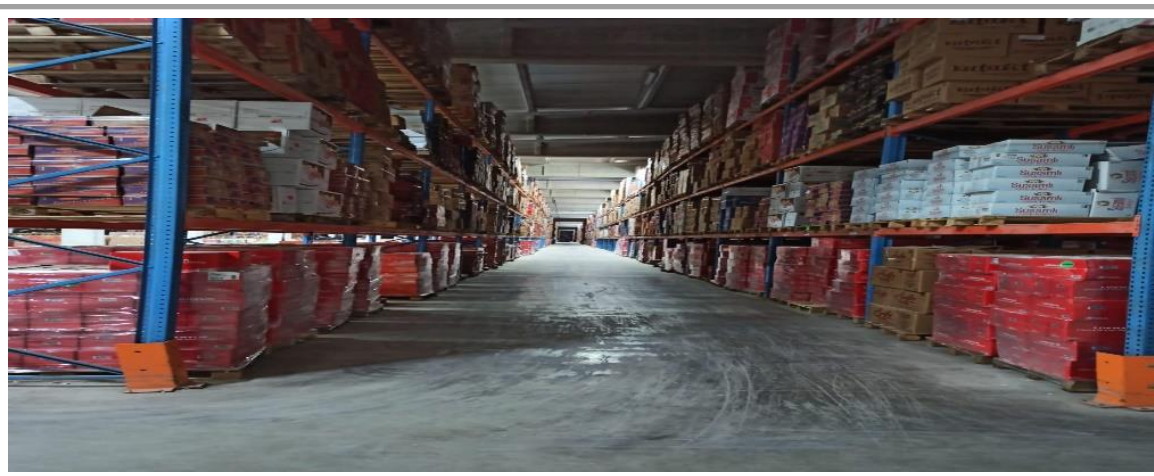

Resim 3: Sırt Sırta Raf Sistemi Görseli

\section{Depoda Kullanılan Bilgi Teknolojileri}

\section{Sap}

Firmanın tasarlamış olduğu depoda bütün süreçleri aktif ve başarılı bir şekilde idare edecek, kâğıt kullanmadan, minimum sürede, minimum çalışan ile hata oranının sıfıra indiren, gerçekleşebilecek sorunların ana kaynağını hemen bulan, süreçleri uzaktan takip edilmesine olanak sağlayan ve faaliyetleri raporlaştırabilen SAP sistemini kullanmaktadır.

\section{El Terminalleri}

Depoda, kullanılan kişiye özel el terminalleri bulunmaktadır. Bu el terminalleri sayesinde personel daha az işgücüyle çalışmakta ve depo sisteminden her zaman haberdar olunmaktadır. Kullanılan bu el terminalleri kişiye özel olduğu için kolayca denetlenmekte, hataların nedeni tespit edilebilmekte ve hızlı bir şekilde hata ortadan kaldırılabilmektedir.

\section{Akıllı Depo}

Akıllı depo sistemi, depodaki bütün süreçlerin entegre olmuş bir şekilde mevcut teknolojiden yararlanarak depolama ve sevkiyat işlemlerini gerçekleştirmesidir. Firmanın nihai ürün deposu akıllı depo özelliğine sahiptir. Bu depoda kullanılan SAP sistemi sayesine entegreli çalışma sağlanmakta ve stok fark1 her an izlenebilmektedir. Akıllı depo sayesinde talebe ve adrese dayalı bir depolama sistemi kullanılmaktadır. Akıllı depo ayrıca 24 saat boyunca deponun izlenmesi sağlanmaktadır.

Tablo 4. Klasik Sistem ve Modern Sistem Farkı

\begin{tabular}{|l|l|}
\hline \multicolumn{1}{|c|}{ KLASiK SiSTEM } & \multicolumn{1}{c|}{ MODERN SiSTEM } \\
\hline Minimum depodaki toplam işçi sayısı: 120 & Depodaki çalışan sayısı: 17 \\
\hline Aylık işci maliyeti: $307.008 \mathrm{TL}$ & Aylık işçi maliyeti: $43.493 \mathrm{TL}$ \\
\hline Y1llık işç maliyeti: $3.684 .096 \mathrm{TL}$ & Y1llık işçi maliyeti: $521.916 \mathrm{TL}$ \\
\hline
\end{tabular}

Tablo 3'te görüldüğü gibi modern sistemde firmaya büyük bir katkısı olan bu akı1lı depo sistemiyle $20.000 \mathrm{~m}^{2}$ lik bir depoda sadece 17 kişi çalışmakta ve bunların aylık asgari $43.493 \mathrm{TL}$ giderleri olmaktadır. Firmadan alınan bilgilere göre, eğer manüel bir depo olmuş olsaydı 17 kişinin işini minimum 120 kişi gerçekleştirebilir ve bunlar için asgari ücret üzerinden toplamda aylık 307.008 TL daha fazla maliyete neden olacaktı. Bu bir firma için ciddi bir maliyettir. Buradan da anlaş1lacağ1 üzere akıllı depo sistemi firmaya maliyet, iş gücü desteği, hız, kalite, güvenlik ve entegreli çalışmayı sağlamaktadır.

\section{Sonuç ve Öneriler}

Lojistik süreçler ilk başlarda sadece nakliye ve stok tutmayı ifade ediyordu. Lojistik zaman içerisinde hizmetlerin hepsini sağlayabilecek bir düzeye gelmiştir. Günümüzde lojistik süreçlerin öneminin artmasıyla dikkatleri üstüne çeken lojistik ifadesi kısaca; tüketicilerin istek ve ihtiyaçlarına bağlı bir şekilde ürün ve hizmetlerin üreticiden tüketiciye doğru aktif ve uygun akışının sağlanması 
için planlama, uygulama ve kontrol edilmesi aşamalarının tümüdür. Bu süreçlerin teknolojiye uyumlu ve başarılı bir şekilde faaliyete geçmesi halinde firmalar için ülke ve hatta dünyada söz sahibi olmayı kazandırabilmektedir.

Lojistik süreçlerinin başında gelen depolama lojistiğin diğer aşamalarını büyük bir oranda etkilemektedir. Bu depolama sürecinin başarılı olması halinde lojistiğin tüm süreçleri olumlu yönde etkileneceklerdir. Depolama sürecinde başarı elde etmenin en önemli unsuru depo tasarımının günümüz teknolojilerine uygun bir şekilde inşa edilmesi ve kullanılmasından geçmektedir. Analizi yapılan firmanın geniş bir akıllı depoya sahip olması, bilişim teknolojilerinden etkin bir şekilde yararlanması ve diğer bütün teknolojik araçların depoda kullanılması firmaya büyük oranda bir fayda sağlamıștır. Firma SAP sistemini kullanmasıyla $40.000 \mathrm{~m}^{2}$ alanda sadece 5 çalıșan ile bașarılı bir adresleme ve yerleştirme sağlamakta olup maliyetleri $\% 80$ civarında düşürmektedir. Ayrıca kullanılan SAP sistemi sayesinde siparişler yalnızca 1 kişiyle ve sadece 30 dakikada hazırlanmakta olup firmaya hız ve zaman konusunda büyük bir avantaj sağlamaktadır. Hazırlanan siparişler modern ekipmanlar sayesinde hızlıca sevkiyatı gerçekleştirilmektedir. Depoda aydınlatmada kullanılan akıllı sensörler ile enerji tasarufu, kurulan karmalar sayesinde 24 saat boyunca izlenebilmesiyle de güvenliği sağlanmaktadır. Akıllı bir depoya sahip olan firma, çalışan sayısını \%80 oranında düşürmekte olup maliyetleri minimum düzeye getirmekte ve hata düzeyini sıfira kadar indirebilmektedir.

Firmanın, depoda otomatik raylı raf sistemini kullanması halinde, maliyet, hız, işgücü desteği, güvenilirlik, sağlamlık ve profesyonellik açısından daha fazla verimlilik elde edilebilecektir. Ayrıca firmanın mevcut deposunda sabit sıcaklığı sağlayacak ısıtma sisteminin kurulması hem işçiler açısından hem de ürünlerin sağlığı açısından uygun olacaktır.

\section{Kaynakça}

Acar, Z. (2010). Depolama ve depo yönetimi, Nobel Yayınevi, Sayfa Sayısı : 192, Isbn No.: 978605-395-225-1, Ankara.

Akal, Z. (1993). Toplam kalite yönetimi ve performans ölçme değerlendirme sistemleri, Verimlilik Dergisi, Mpm Yayınlar1, Ankara.

Baskak, M. (2002). Depo tasarımı ve depo yönetimi, ders notları, İstanbul Teknik Üniversitesi, Fen Bilimleri Enstitüsü, İstanbul.

Dinç, F. (2010). Depo ve depo içi ekipmanlar, Beykoz Lojistik Meslek Yüksekokulu İktisadi ve İdari Programlar Bölümü, Yüksek Lisans Tezi, İstanbul.

Güler, E. (2006). Depo yönetiminde bilgi teknolojileri kullanımı, Yüksek Lisans Tezi, İstanbul Teknik Üniversitesi, Fen Bilimleri Enstitüsü, İstanbul.

Kumuk, C. (2005). Depolama sistemleri ve ekipmanları, Lojistik Kamp 2005 Sunumları, Y1ldı Teknik Üniversitesi, İstanbul.

Tompkins, J. A., ve Harmelink, D. A. (2004). The supply chain handbook. Tompkins Press.

Yıldıztekin, A. (2004). Depolama, hızı sıfır olan taşımacılıktır, Ambar Dergisi, 9, 20-21. 143.

https://www.moderncikolata.com.tr/page/about-us\# 